\title{
How has the treatment of hypercholesterolemia in Poland changed over the last six years?
}

\author{
Agnieszka Kapłon-Cieślicka, Marcin Michalak, Łukasz Kołtowski, Krzysztof J. Filipiak
}

$1^{\text {st }}$ Chair and Department of Cardiology, Medical University of Warsaw, Poland

\begin{abstract}
Background: To assess changes in the treatment of hypercholesterolemia in Polish ambulatory care over the last 6 years.

Methods: Data were obtained from two separate questionnaire-based studies, conducted in 2009 and 2015. The analysis included only those patient visits, which were associated with modifications of previous hypercholesterolemia treatment (1924 visits from the year 2009 and 1888 visits from the year 2015). Results: In the present registry, there was a $19 \mathrm{mg} / \mathrm{dL}$ reduction in the level of total cholesterol and a $17 \mathrm{mg} / \mathrm{dL}$ reduction in the level of low-density lipoprotein compared to year 2009. In both registries, the most common reason for treatment modification was failure to achieve therapeutic goals. Compared to year 2009, there was an increase in the proportion of patients treated with atorvastatin and a reduction in the proportion of patients treated with simvastatin at baseline; additionally, in year 2015, $10 \%$ of patients received rosuvastatin. After therapy modification, there was a similar increase in the proportion of patients treated with a statin-fibrate combination in both registries. However, at present, ezetimibe was significantly less often added to previous therapy. In both registries, therapy modification led to an increase in the mean doses of the most commonly used statins, although presently, this increase was smaller than in 2009.

Conclusions: The most favorable change in the treatment of hypercholesterolemia is an increase in the proportion of patients treated with strong statins. Unfavorable changes include a reduction in the frequency of polytherapy, especially with ezetimibe, and a tendency to prescribe lower, ineffective statin doses. (Cardiol J 2017; 24, 3: 266-275)
\end{abstract}

Key words: cholesterol, low-density lipoprotein, statins, fibrates, ezetimibe, combination therapy

\section{Introduction}

According to the European Society of Cardiology (ESC), hypercholesterolemia is defined as total cholesterol concentration of above $190 \mathrm{mg} / \mathrm{dL}$ and/ /or low-density lipoprotein (LDL) concentration of above $115 \mathrm{mg} / \mathrm{dL}$ [1]. Hypercholesterolemia is among the most important and at the same time, the most common risk factors of atherosclerosis, prevalent in 18 million $(61 \%)$ adults in Poland $[2,3]$. Clinical trials and meta-analyses have unequivocally demonstrated that cardiovascular risk constantly decreases with decreasing LDL concentrations, and that every reduction of $40 \mathrm{mg} /$ $/ \mathrm{dL}$ in LDL concentration results in a $20 \%$-reduction in cardiovascular morbidity and mortality [4]. This observation has led to a gradual reduction in target LDL concentration in patients treated for hypercholesterolemia over the last few years [5-8]. Another important trend in hypercholesterolemia treatment is a constant, progressive individualization of therapeutic goals. According to the ESC guidelines, target LDL concentration should be based on an individual assessment of total cardiovascular risk [6-8].

Address for correspondence: Agnieszka Kapłon-Cieślicka, $\mathrm{MD}, \mathrm{PhD}, 1^{\text {st }}$ Chair and Department of Cardiology,

Medical University of Warsaw, ul. Banacha 1a, 02-097 Warszawa, Poland, tel: +48 22 5992958, fax: +48 22 5991957,

e-mail: agnieszka.kaplon@gmail.com

Received: 24.01.2016 Accepted: 14.12.2016 
The aim of the study was to evaluate changes in the treatment of hypercholesterolemia in Polish cardiologic ambulatory care over the last 6 years.

\section{Methods}

The current analysis was based on the results of two, separate questionnaire studies, conducted almost 6 years apart (i.e. between August and September 2009, and between January and March 2015). In each of these studies, 130 cardiologists participated, who had been professionally active for from 2 to 30 years, had treated at least 80 hypercholesterolemia patients monthly and worked in cardiologic ambulatory care in provincial cities or other cities with the greatest number of cardiologists (maintaining the proportion in the number of cardiologists working in provincial and non-provincial cities; random quota selection). Table 1 shows the number of cardiologists participating in the 2009 and the 2015 registry in relation to city type and size. Table 2 presents numbers of participating cardiologists and patients in relation to Poland's provinces. Out of the 16 provinces in Poland, only one (Lubusz) was not involved in these surveys. Out of 130 cardiologists engaged in the study in year $2015,39(30 \%)$ had previously participated in the 2009 registry. In year 2009 , there were 88 sites participating in the survey. In the 2015 registry, 120 sites were involved, including 25 (21\%) sites which had participated in the 2009 survey.

Both registries included only those patient visits which were associated with modifications of previous hypercholesterolemia treatment and which satisfied at least one of the following conditions: addition of another hypolipidemic agent, cessation of hitherto used hypolipidemic therapy, replacement of previously used hypolipidemic drug and/or changes in dosing of a hypolipidemic agent. Every participating cardiologist was asked to include 15 consecutive visits that fulfilled those conditions.

Both studies were conducted by an independent research company Sequence HC Partners and funded from research grants of MSD Poland. Scientific description and interpretation of the results was conducted in the $1^{\text {st }}$ Chair and Department of Cardiology, Medical University of Warsaw, Poland.

\section{Statistical analysis}

Qualitative variables are presented as relative frequencies. Quantitative variables are presented as a mean value \pm standard deviation (SD). The $z$-test for two independent proportions was used
Table 1. Number of cardiologists participating in the 2009 and the 2015 registry in relation to city type and city size.

\begin{tabular}{lcc}
\hline & \multicolumn{2}{c}{$\begin{array}{c}\text { No. of participating } \\
\text { cardiologists }\end{array}$} \\
\cline { 2 - 3 } & $\begin{array}{c}2009 \\
\text { registry }\end{array}$ & $\begin{array}{c}2015 \\
\text { registry }\end{array}$ \\
\hline City type & & \\
Provincial* & 106 & 88 \\
Non-provincial** & 24 & 42 \\
Total & 130 & 130 \\
City size (population) & & \\
$<100,000$ & 22 & 31 \\
100,000-200,000 & 16 & 23 \\
200,000-500,000 & 37 & 30 \\
$>500,000$ & 55 & 46 \\
Total & 130 & 130 \\
\hline
\end{tabular}

* Provincial city, i.e. a capital of a province

**Non-provincial city, i.e. a city or town which is not a capital of a province

to determine statistical significance of differences between the 2009 and the 2015 population. P-values of $<0.05$ were considered significant. Some portion of data obtained from both registries has been presented in previous publications [9-11].

\section{Results}

\section{Comparison of clinical characteristics of both study populations}

A total of 1924 visits were included in the 2009 registry, and 1888 visits in the 2015 registry. Clinical characteristics of both populations have been presented in previous publications [9-11]. Table 3 presents a comparison of clinical characteristics of the two populations.

\section{Achievement of lipid therapeutic goals in both registries}

In comparison to the 2009 population, in the 2015 registry the following observations were recorded: a reduction of mean total cholesterol concentration by $19 \mathrm{mg} / \mathrm{dL}$, of mean LDL concentration by $17 \mathrm{mg} / \mathrm{dL}$ and of mean triglyceride concentration by $13 \mathrm{mg} / \mathrm{dL}$, as well as an increase in mean high-density lipoprotein (HDL) concentration by $4 \mathrm{mg} / \mathrm{dL}$ ( $\mathrm{p}<0.05$ for all differences) (Fig. 1). In year 2015, a proportion of patients who achieved an LDL concentration below $100 \mathrm{mg} / \mathrm{dL}$ more than doubled (from $12 \%$ to $27 \%, \mathrm{p}<0.05$ ) 
Table 2. Number of cardiologists and patients participating in the 2009 and the 2015 registry in relation to provinces.

\begin{tabular}{|c|c|c|c|c|}
\hline \multirow[t]{2}{*}{ Province } & \multicolumn{2}{|c|}{2009 registry } & \multicolumn{2}{|c|}{2015 registry } \\
\hline & $\begin{array}{c}\text { Number of } \\
\text { cardiologists }\end{array}$ & $\begin{array}{l}\text { Number of } \\
\text { patients }\end{array}$ & $\begin{array}{l}\text { Number of } \\
\text { cardiologists }\end{array}$ & $\begin{array}{c}\text { Number of } \\
\text { patients }\end{array}$ \\
\hline Lower Silesian & 11 & 165 & 12 & 166 \\
\hline Kuyavian-Pomeranian & 8 & 120 & 8 & 118 \\
\hline Lublin & 4 & 56 & 4 & 59 \\
\hline Lodz & 6 & 90 & 6 & 90 \\
\hline Lesser Poland & 11 & 165 & 11 & 158 \\
\hline Masovian & 31 & 460 & 24 & 348 \\
\hline Opole & 2 & 27 & 1 & 10 \\
\hline Podkarpackie & 3 & 45 & 4 & 60 \\
\hline Podlaskie & 3 & 45 & 2 & 30 \\
\hline Pomeranian & 7 & 105 & 8 & 120 \\
\hline Silesian & 20 & 292 & 20 & 290 \\
\hline Swietokrzyskie & 2 & 30 & 3 & 45 \\
\hline Warmian-Masurian & 4 & 58 & 3 & 45 \\
\hline Greater Poland & 12 & 176 & 16 & 231 \\
\hline West Pomeranian & 6 & 90 & 8 & 118 \\
\hline Total & 130 & 1924 & 130 & 1888 \\
\hline
\end{tabular}

Table 3. Clinical characteristics of the studied populations.

\begin{tabular}{lccc}
\hline & $\begin{array}{c}\text { 2009 registry } \\
\text { (n = 1924) }\end{array}$ & $\begin{array}{c}\text { 2015 registry } \\
\text { (n = 1888) }\end{array}$ & P \\
\hline Age [years] & $63.0 \pm 10.4$ & $63.5 \pm 11.2$ & NS \\
Women & $47 \%$ & $44 \%$ & $<0.05$ \\
Body mass index $\left[\mathrm{kg} / \mathrm{m}^{2}\right]$ & $28.5 \pm 4.9$ & $28.5 \pm 4.9$ & $\mathrm{NS}$ \\
Obesity & $40 \%$ & $34 \%$ & $<0.05$ \\
Duration of hypercholesterolemia treatment [years] & $4.4 \pm 4.3$ & $6.6 \pm 4.7$ & $<0.05$ \\
Familial hypercholesterolemia* & $25 \%$ & $17 \%$ & $<0.05$ \\
Arterial hypertension & $86 \%$ & $89 \%$ & $<0.05$ \\
Coronary artery disease & $68 \%$ & $57 \%$ & $<0.05$ \\
Previous acute coronary syndrome & $47 \%$ & $36 \%$ & $<0.05$ \\
Previous coronary revascularization & $32 \%$ & $28 \%$ & $<0.05$ \\
Chronic heart failure & $21 \%$ & $17 \%$ & $<0.05$ \\
Previous cerebral stroke & $11 \%$ & $8 \%$ & $<0.05$ \\
Peripheral artery disease & $16 \%$ & $13 \%$ & $<0.05$ \\
Type 2 diabetes & $34 \%$ & $33 \%$ & $\mathrm{NS}$ \\
Smoking & $42 \%$ & $38 \%$ & $<0.05$ \\
Primary prevention & $28 \%$ & $34 \%$ & $<0.05$ \\
Secondary prevention & (2) & $66 \%$ & $<0.05$ \\
\hline
\end{tabular}

*Diagnosis made at the discretion of participating cardiologists

${ }^{*}$ * I.e. patients with a history of coronary artery disease, cerebral stroke or peripheral artery disease; NS - non-significant (i.e. $p \geq 0.05$ ) 


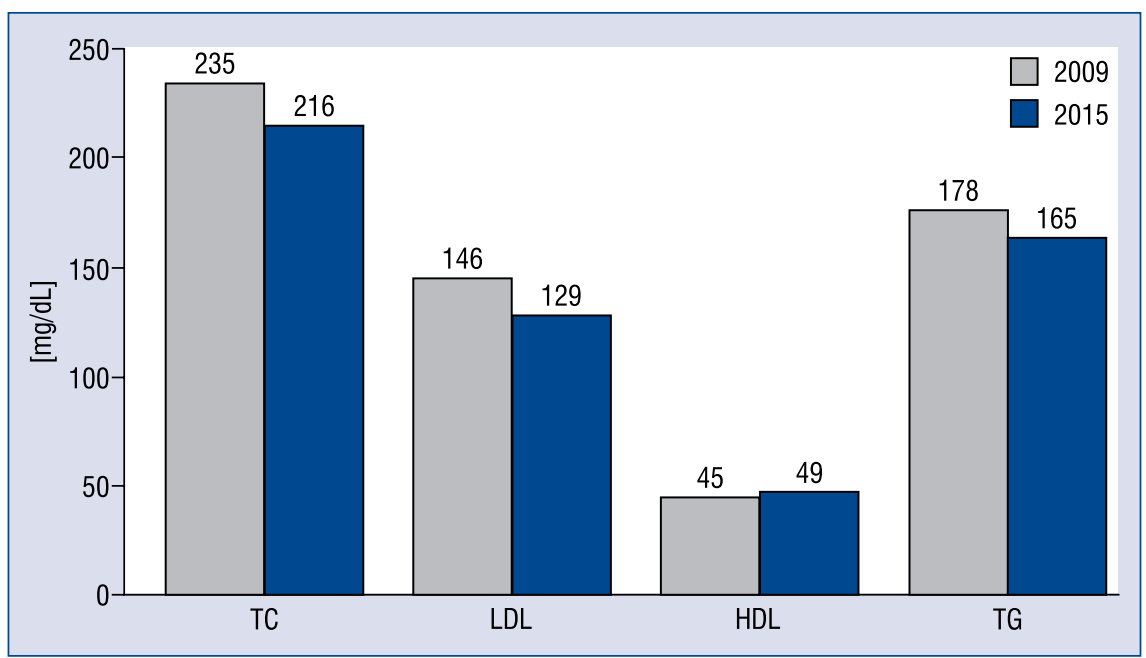

Figure 1. Mean concentrations of total cholesterol (TC), low-density lipoprotein (LDL), high-density lipoprotein (HDL) and triglycerides (TG) in the 2009 and 2015 registry (based on [9-11], modified).

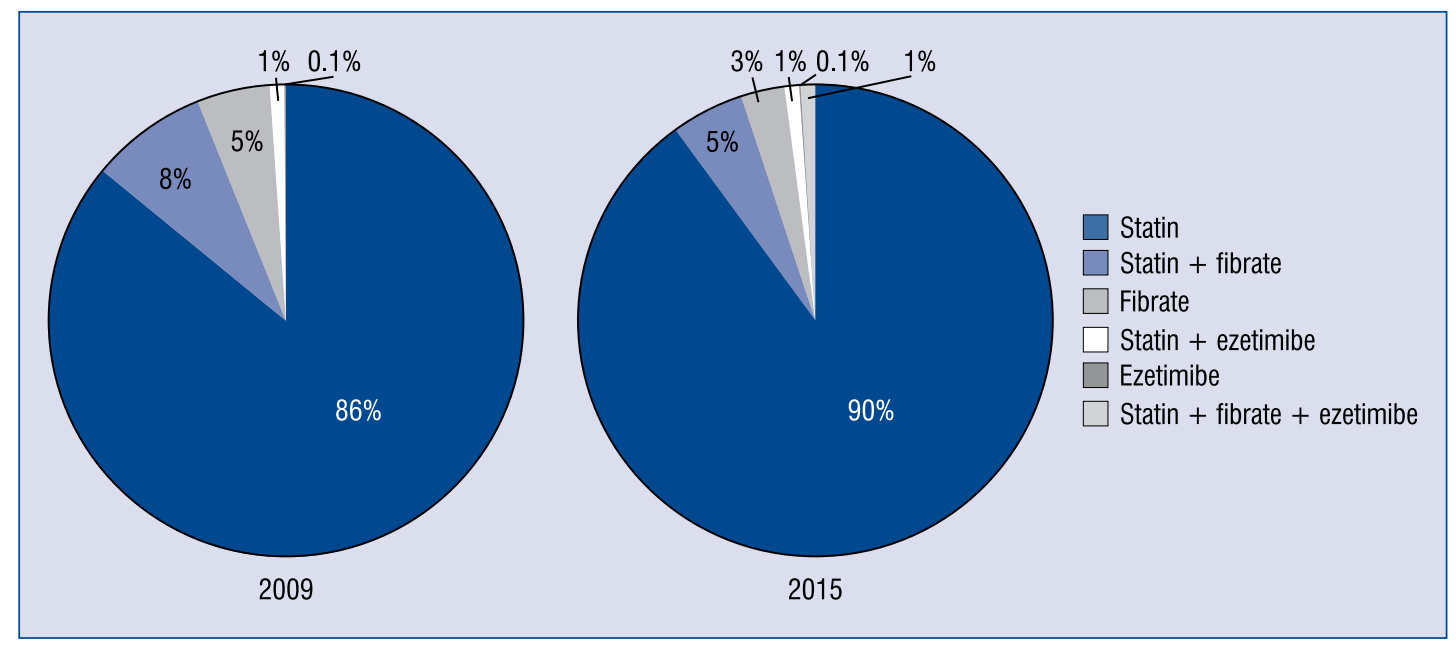

Figure 2. Pharmacotherapy of hypercholesterolemia before modification in the 2009 and 2015 registry (based on [9-11], modified).

[9-11]. The proportion of patients with an LDL concentration below $70 \mathrm{mg} / \mathrm{dL}$ had also significantly increased (from $2 \%$ in the 2009 registry to $10 \%$ in the 2015 registry, $\mathrm{p}<0.05)$. Moreover, the time between consecutive lipid testing was significantly shorter in 2015, with mean time from the last total cholesterol testing shorter by 31 days, mean time from the last LDL cholesterol testing - by 30 days, mean time from the last HDL cholesterol testing — by 38 days, and mean time from the last triglyceride testing shorter by 36 days in 2015 as compared to 2009 ( $\mathrm{p}<0.05$ for all differences).

\section{Baseline hypercholesterolemia treatment in both registries}

Figure 2 demonstrates baseline hypolipidemic treatment in years 2009 and 2015 . While comparing baseline statin treatment in both registries, one should note a reversal in the proportion of patients treated with simvastatin and atorvastatin (with simvastatin used in $62 \%$ of patients in 2009 , and in $30 \%$ of patients in 2015 , and atorvastatin used in $31 \%$ of patients in 2009 , and in $56 \%$ of patients in 2015), as well as an introduction of rosuvastatin (registered in year 2009 and not yet used in 


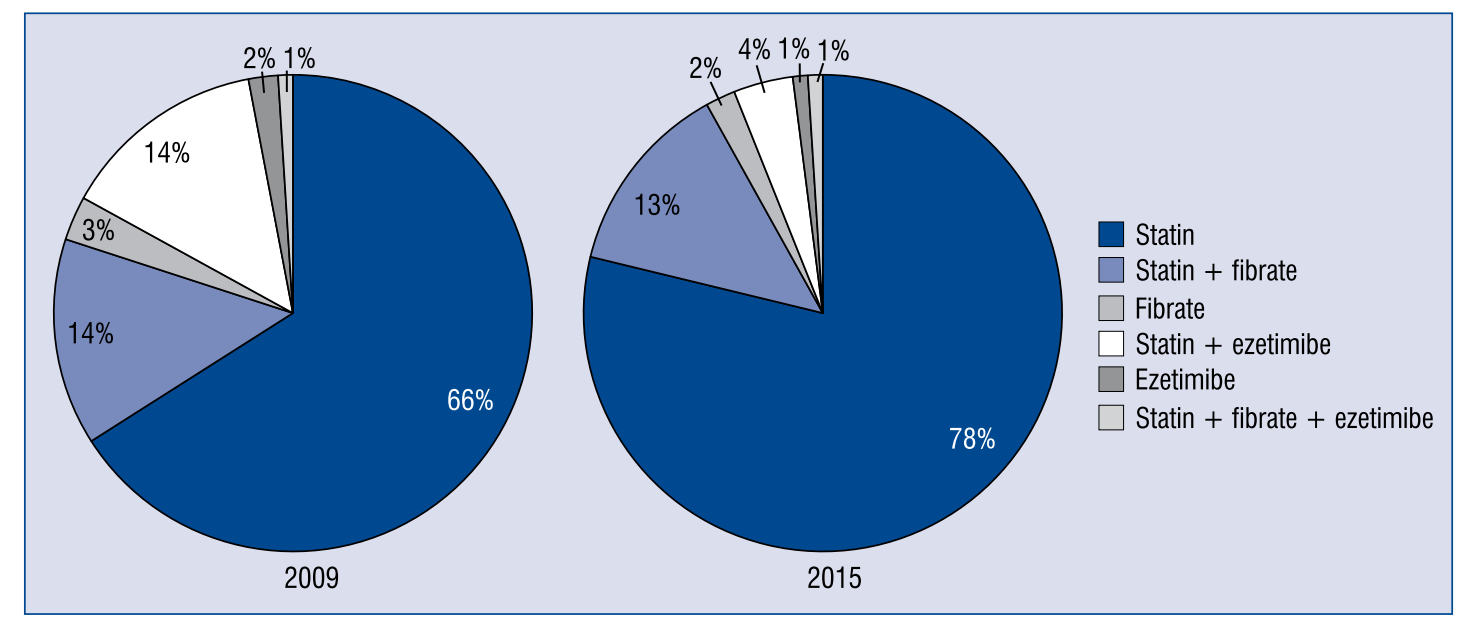

Figure 3. Pharmacotherapy of hypercholesterolemia after modification in the 2009 and 2015 registry (based on [9-11], modified).

patients from the 2009 registry), which was given to $10 \%$ of patients in year 2015 ( $p<0.05$ for all differences) [9-11]. The frequency of treatment with other statins (i.e. pravastatin, fluvastatin and lovastatin) was negligible in both registries.

In the 2015 survey, less patients were treated with fibrates compared to the 2009 registry (9\% vs. $13 \%$, respectively, $\mathrm{p}<0.05)$. In both registries, the most commonly used fibrate was fenofibrate, which was given to $10 \%$ of the whole study group in 2009 and to $8 \%$ of the whole study group in 2015 ( $p$-value non-significant); other patients received ciprofibrate.

\section{Hypercholesterolemia treatment after therapy modification in both registries}

In both registries, the most common reason for therapy modification was failure to achieve therapeutic goals (in 84\% patients in 2009 and in $75 \%$ patients in 2015, $\mathrm{p}<0.05$ ). Compared to the previous registry, in year 2015 , other reasons for therapy modification significantly more often included: fear of future adverse effects $(11 \%$ vs. $9 \%$ in $2009, \mathrm{p}<0.05$ ), statin intolerance $(6 \%$ vs. $4 \%$ in $2009, \mathrm{p}<0.05)$ and achievement of therapeutic goal ( $8 \%$ vs. $2 \%$ in $2009, \mathrm{p}<0.05)$. On the other hand, adverse effects were less common in year 2015 than in year 2009 ( $5 \%$ in 2015 vs. $7 \%$ in $2009, \mathrm{p}<0.05$ ).

Figure 3 shows hypolipidemic treatment after therapy modification in the 2009 and 2015 registries. In both registries, the most common type of modification was a change (most often - an increase) in statin dose and a replacement of one statin with another - these two modifications were more often introduced (by 12\%) in year 2015 in contrast with 2009. Compared to the 2009 registry, in year 2015, ezetimibe was significantly less often added to the hitherto therapy: in 2009 ezetimibe was added in $16 \%$ of cases, which was the third most common type of therapy modification, while in 2015 ezetimibe was added only in $5 \%$ of cases $(\mathrm{p}<0.05)$. On the other hand, fibrates were added to therapy with a similar frequency in both registries (in $12 \%$ and in $11 \%$ of patients in year 2009 and 2015, respectively, p-value non-significant).

In both registries, therapy modification resulted in a reduction in the proportion of patients treated with simvastatin (down to $37 \%$ in year 2009 , and down to $9 \%$ in year 2015). An increase in the proportion of patients receiving atorvastatin was also noted (up to $57 \%$ in 2009 and up to $62 \%$ in 2015). Additionally, in year 2015, after therapy modification, there was a further increase in the frequency of rosuvastatin treatment (up to 25\%) [9-11].

In both registries, among the patients who, after therapy modification, were using the same statin molecule, its dose was increased in more than a half of them (in 55\% in 2009 and in 57\% in 2015). However, compared to year 2009, in year 2015, cardiologists more often reduced the dose of hitherto used statin (in 16\% in 2009 and in $25 \%$ in $2015, \mathrm{p}<0.05)$. In both registries, the most common type of dosing modification, for both simvastatin and atorvastatin, was an increase from a dose of $20 \mathrm{mg}$ per day to a dose of $40 \mathrm{mg}$ per day. After therapy modification, the most frequently 
used atorvastatin dose in both registries was a dose of $40 \mathrm{mg}$ daily, which was prescribed to $60 \%$ of atorvastatin-treated patients in 2009, and in $47 \%$ of atorvastatin-treated patients in year 2015. Atorvastatin $80 \mathrm{mg}$ daily was rarely prescribed in both registries, with only 18 patients $(0.9 \%$ of the whole study group; $3 \%$ of atorvastatin-treated patients) at baseline, and 45 patients ( $2 \%$ of the whole study group; $4 \%$ of atorvastatin-treated patients) after treatment modification in year 2009. In the 2015 registry, only 40 patients ( $2 \%$ of the whole study group; $4 \%$ of atorvastatin-treated patients) were on atorvastatin $80 \mathrm{mg}$ daily at baseline, and 70 patients (4\% of the whole study group; $6 \%$ of atorvastatintreated patients) were on atorvastatin $80 \mathrm{mg}$ after treatment modification. For simvastatin, the most frequently prescribed dose after therapy modification was a dose of $40 \mathrm{mg}$ daily in year 2009 (55\% of simvastatin-treated patients), and $20 \mathrm{mg}$ daily in year 2015 (42\% of simvastatin-treated patients). After therapy modification, mean atorvastatin dose increased by $7.9 \mathrm{mg}$ daily (up to $34.4 \mathrm{mg}$ daily) in year 2009 , and by $5.6 \mathrm{mg}$ daily (up to $33.3 \mathrm{mg}$ daily) in year 2015; mean simvastatin dose increased by $8.7 \mathrm{mg}$ daily (up to $32.4 \mathrm{mg}$ daily) in 2009 , and only by $3.4 \mathrm{mg}$ daily (up to $26.0 \mathrm{mg}$ daily) in 2015 ; mean rosuvastatin dose increased in 2015 by $3.9 \mathrm{mg}$ daily (up to $21.6 \mathrm{mg}$ daily).

In year 2009, therapy modification resulted in an increase in the frequency of fenofibrate use, as it was prescribed to $17.5 \%$ of the whole studied group (among 18\% fibrate-treated patients) and in a reduction in the frequency of ciprofibrate use (from $2.4 \%$ to $0.5 \%$ of the whole group). However, mean fenofibrate dose decreased from $217 \mathrm{mg}$ to $208 \mathrm{mg}$ daily. Similarly, in year 2015, most of the fibrate-treated patients received fenofibrate (after therapy modification, ciprofibrate was used only in $0.7 \%$ of the whole group studied). No data on fibrate dosing before and after therapy modification in 2015 were obtained.

In both registries, mean ezetimibe dose was $10 \mathrm{mg}$ daily (both before and after therapy modification).

\section{Discussion}

The analyzed data were obtained during two questionnaire-based surveys conducted among cardiologists working in ambulatory care. Criteria for selection of participating cardiologists, inclusion criteria for patient visits, as well as the type and scope of gathered data were the same in 2009 and in 2015, which enabled a direct comparison of the results [9-11]. Thus, it may be assumed that the presented data adequately reflect recent changes in hypercholesterolemia treatment in cardiologic ambulatory care in Poland.

In order to interpret these data correctly, one must take into account that both the 2009 and the 2015 registry included patients in whom, for various reasons (most frequently due to failure to achieve therapeutic goals), there was a need for hypolipidemic treatment modification, most frequently for intensification. Thus, the studied groups are not representative for the whole population of Polish adults treated for hypercholesterolemia in ambulatory care.

Compared to the 2009 population, patients included in the 2015 registry had, despite being the same age, had lower cardiovascular risk, which might, on one hand, imply some minor improvement in general health condition in this age group, (although due to the relatively small size of the studied group and particular study inclusion criteria these results cannot be extrapolated to the whole Polish population), and, on the other hand, it may demonstrate a tendency for a more timely referral of patients burdened with cardiac risk factors to specialist cardiologic care, even before they develop clinically overt cardiovascular disease, such as coronary artery disease or chronic heart failure.

Compared to the population studied in year 2009 , patients in whom hypolipidemic therapy was modified in 2015 were characterized by a better lipid control. This is probably predominantly due to the changes in the 2011 ESC guidelines on dyslipidemias which, compared to the previous guidelines, have decreased target LDL concentrations in patients with high and very high cardiovascular risk and changed the definition of high and very high risk patients including new patient subgroups (e.g. patients with chronic kidney disease or subjects with high risk of cardiovascular death according to the SCORE chart) into these groups $[5,6]$. The differences in baseline LDL concentration between year 2009 and 2015 reflect the tendency of attending cardiologists to intensify hypolipidemic treatment at an earlier stage. Other potential factors that might have contributed to the observed differences in LDL levels between the two registries could also include: a more timely referral of patients burdened with cardiac risk factors to specialized cardiologic care by general practitioners (GPs) (e.g. due to increasing awareness of the importance of LDL control among both GPs and patients themselves, or due to changes in the healthcare system), more intensive lipid-lowering 
treatment, including both life-style modifications and pharmacotherapy, socio-economic fluctuations, or even, though it remains to be tested, changes in LDL concentration on the population level.

Another favorable change, compared to year 2009 , is the observed reduction in time period between consecutive lipid testing - in the 2015 report its length was approximately 2 months, which is in line with both the 2011 and the current, 2016 ESC guidelines (according to the guidelines after therapy initiation or modification, subsequent lipid testing should be performed after $8 \pm 4$ weeks) $[6,7,11]$.

Despite favorable changes in the lipid profile of patients in whom hypolipidemic therapy was modified in year 2015, the obtained mean LDL cholesterol level of $129 \mathrm{mg} / \mathrm{dL}$ is still significantly above the target concentration even for the low and moderate cardiovascular risk groups $(<115$ $\mathrm{mg} / \mathrm{dL}$ ), whereas more than a half of the analyzed population included patients with very high total cardiovascular risk, for whom the target LDL level is below $70 \mathrm{mg} / \mathrm{dL}[6,7,11]$.

An unfavorable change, compared to the 2009 data, is a significant reduction in the frequency of combination therapy (especially with statin and ezetimibe) in the hypolipidemic treatment of patients who did not reach their therapeutic goals. Whereas the initial proportion of patients on combination therapy was similar in both registries (9\% in year 2009 and $7 \%$ in year 2015), the proportion of patients on combination therapy after treatment modification increased to $29 \%$ in year 2009 , and only to $18 \%$ in year 2015 . This difference was mainly due to the fact, that in year 2015 ezetimibe was more than 3 times less often added to therapy than in year 2009 (fibrates mainly fenofibrate - were added to treatment with a similar frequency in both registries). As a result, in year 2009 , after therapy modification, the number of patients treated with a statin-ezetimibe combination (14\%) was equal to the number of patients treated with a statin-fibrate combination (14\%), with a total proportion of patients treated with ezetimibe in monotherapy or in combination therapy as high as $17 \%$. In year 2015 , a statinezetimibe combination was prescribed over 3 times less often than a statin-fibrate combination (i.e. only in $4 \%$ of patients), with a total proportion of patients treated with ezetimibe, in monotherapy or in combination therapy, being as low as $6 \%$. A triple combination of statin, ezetimibe and fibrate was rarely prescribed in both registries.

Thus, in year 2015, the choice of hypolipidemic drugs added to statins in patients who did not reach their therapeutic goals was, in fact, limited to fenofibrate. Such a drastic reduction in the frequency of ezetimibe use might be explained by the disadvantageous results of the ENHANCE study, which showed no difference in carotid intima-media thickness with combined simvastatin-ezetimibe therapy compared with simvastatin alone, despite greater reductions in C-reactive protein and LDL concentrations on ezetimibe [12]. The results of the ENHANCE trial, published in 2008, could have triggered a progressive reduction in the prescription of ezetimibe, which might not have been entirely evident by 2009 , but has probably continued thereafter.

The observed reduction in ezetimibe use in our study should be considered unfavorable, especially in the context of the recently published results of the IMPROVE-IT trial, which has demonstrated an advantage of a simvastatin-ezetimibe combination therapy over simvastatin monotherapy, i.e. a reduction in the risk of a combined clinical endpoint (cardiovascular death, myocardial infarction, unstable angina, need for coronary revascularization and ischemic stroke) in patients after acute coronary syndromes [13]. However, our second survey was conducted at the beginning of year 2015, prior to the publication of the results of the IMPROVE-IT trial late in 2015. Thus, another increase in the frequency of ezetimibe use might be anticipated in 2016 and in years to come.

Given no reduction in cardiovascular outcomes with fenofibrate in the ACCORD trial, published in 2010 , as well as lower mean triglyceride concentration in the 2015 registry, a reduction in fibrate use in 2015 as compared to 2009 was to be anticipated [14]. Indeed, at baseline less patients were treated with fibrates in the 2015 registry compared to the 2009 survey. However, surprisingly, the proportion of patients in whom fibrates were added to previous therapy during the index visit did not significantly decrease. It could be hypothesized that a similar proportion of patients who were prescribed fibrates during the index visit in the 2009 and the 2015 registry might be related to: 1 ) the fact that no clear benefit of fenofibrate therapy seen in the ACCORD trial (2010) was concordant with the results of the previous FIELD study (2005); 2) the fact that fibrates remain the most effective agents lowering triglyceride concentrations, (and in both registries approximately one quarter of patients had a triglyceride level of above $200 \mathrm{mg} / \mathrm{dL}$ despite hitherto hypolipidemic treatment) - although it needs to be emphasized that in patients at high cardiovascular risk with moderately elevated 
triglyceride levels, statins (especially more potent statins, such as atorvastatin or rosuvastatin) should be the first drugs of choice, as they reduce both triglyceride concentration and cardiovascular mortality $[6,7,14,15]$.

A beneficial tendency, observed in the 2015 registry, is an increase in the use of "strong" statins (atorvastatin, rosuvastatin) at the expense of "weaker" statins. In year 2009, simvastatin was initially given to almost two-thirds of all patients, and atorvastatin - to less than one third. Therapy modification in year 2009 led to a reversal of these proportions. In year 2015, an initial proportion of simvastatin-atorvastatin use was already similar to the proportion observed after therapy modification in year 2009, and modification of treatment in 2015 resulted in a further increase in the frequency of atorvastatin use, at the expense of simvastatin. Additionally, in year 2015, rosuvastatin was given to one tenth of patients at baseline, and after therapy modification, to as many as a quarter of patients. On the other hand, statins were given in suboptimal doses - and thus, although atorvastatin is prevalently prescribed more frequently than 6 years ago, its mean dose and mean increase in its dose after therapy modification were lower than in year 2009 . It is also clearly visible that in year 2015 , doctors tended to avoid high doses of simvastatin, which might be explained by the negative opinion of the American Food and Drug Administration (FDA) on its use in high doses (published in year 2011), especially if we take into account that the fear of future adverse effects was the reason for therapy modification in one tenth of cases [16]. However, given the unsatisfactory lipid control in the study group it seems difficult to understand, why this situation resulted, in some of the patients, in continuation of simvastatin in a lower dose, instead of replacing it with a stronger statin.

Compared to the 2009 registry, in year 2015, statin dose was more frequently reduced. In year 2015 , statin dose was reduced in as many as a quarter of all patients, even though statin intolerance was reported in only $6 \%$ of cases. In year 2015 , it was also more common than in year 2009 to modify therapy due to fear of adverse events, despite the fact that their actual frequency had decreased. Furthermore, in year 2015, therapy modification was also more often reported to be due to the "achievement of a therapeutic goal" - a situation which should rather lead to continuation of the previous, successful pharmacotherapy. The recently growing fear for adverse effects of statins could have been a result of an FDA warning (published in 2012) on the increased risk of type 2 diabetes development in statin-treated patients [17]. Although clinical studies and meta-analyses conducted so far have confirmed the existence of this relationship, the effect of statin therapy on glucose homeostasis seems relatively minor - in non-diabetic patients treated with statins fasting glycemia is on average only $3 \mathrm{mg} / \mathrm{dL}$ higher than in subjects not receiving these drugs, and in diabetic patients statin use is associated with an increase in the proportion of glycated hemoglobin $\left(\mathrm{HbA}_{1 \mathrm{c}}\right)$ by $0.12 \%$ compared to diabetics not treated with statins [18-20]. Although the results of a recently published METSIM study suggest that the risk of type 2 diabetes development on statin therapy might be higher than previously anticipated, still, the undeniable benefits of statin use in patients with high or very high total cardiovascular risk overweight the potential risk of their adverse effects [21].

Apart from the present analysis, there is a considerable lack of data on current trends in hypolipidemic therapy in Poland. The largest study recently that analyzed hypolipidemic treatment in Polish outpatients was the 3ST-POL study published in 2013 [22]. However, it specifically focused on statin therapy only. The 3ST-POL study included 49,950 Polish ambulatory patients receiving statins. The most frequently used statins were atorvastatin (49\% of patients) and simvastatin (45\%), which is consistent with the trend observed in our registries, with a growing proportion of patients receiving atorvastatin (from $31 \%$ in 2009 to $56 \%$ in 2015) and a decreasing proportion of patients on simvastatin (from $62 \%$ in 2009 to $30 \%$ in 2015). The most commonly prescribed dosage for both statins in the 3ST-POL study was $20 \mathrm{mg}$ daily, which is similar to what was observed in both our registries before therapy modification. High-risk patients accounted for $72 \%$ of all 3ST-POL patients. Their mean total cholesterol $(245 \mathrm{mg} / \mathrm{dL})$ and LDL cholesterol concentrations ( $143 \mathrm{mg} / \mathrm{dL}$ ) were comparable to the levels observed in the 2009 registry, though higher than in the 2015 survey. This may be attributable to the fact that, contrary to the present analyses, in the 3ST-POL study, $79 \%$ patients were treated by GPs and only $16 \%$ by cardiologists. Of note, patients under specialist care more often reached target total cholesterol level as compared to patients treated by GPs [22].

In the Polish cohort of the EUROASPIRE III survey (2006-2007), mean total and LDL cholesterol concentrations at ambulatory visit (at least 6 months after a coronary event) were significantly lower than in both registries $(162 \mathrm{mg} / \mathrm{dL}$ and 
$89 \mathrm{mg} / \mathrm{dL}$, respectively) with $93 \%$ of patients on statin therapy [23]. This may reflect the fact that the EUROASPIRE survey was conducted in reference cardiac centers and thus encompassed a selected population, not necessarily representative of the majority of Polish patients treated for hypercholesterolemia. An analysis of the Polish subgroup of the latest EUROASPIRE IV survey has as yet not been published [24].

\section{Limitations of the study}

Both registries in this study included only visits associated with modifications of previous hypolipidemic therapy. Furthermore, only $21 \%$ of sites and $30 \%$ of cardiologists involved in the 2015 survey, had previously participated in the 2009 registry. Despite the fact that all but one of Poland's provinces were included in the surveys, as well as an attempt to maintain proportions in the number of cardiologists working in provincial (i.e. capitals of provinces) and non-provincial (i.e. other than provincial) cities similar to that observed in the whole country, it needs to be emphasized that the results of the study cannot be considered representative for the whole population of Polish adults treated for hypercholesterolemia in ambulatory care.

The diagnosis of familial hypercholesterolemia was made at the discretion of the participating cardiologists ("yes" vs. "no" in the registry questionnaires) and was not objectively verified by the investigators, resulting in an unexpectedly high proportion of this diagnosis in both registries.

\section{Conclusions}

Among the changes observed in the treatment of hypercholesterolemia over the last 6 years, beneficial ones include an increase in the use of more potent statins (atorvastatin, rosuvastatin), achievement of lower total cholesterol and LDL concentrations, even in the population with suboptimal lipid control, and reduction of time between consecutive lipid testing. Unfavorable changes include a significant reduction in the use of combination therapy, especially with ezetimibe, in patients who did not reach their therapeutic goals and a tendency to prescribe lower, suboptimal statin doses.

\section{Acknowledgements}

The authors would like to thank Sequence HC Partners for conducting questionnaires and for preparing the statistical data report. The authors would also like to give their special thanks to the MSD Poland, in particular to Mr Rafał Jaworski for the content based support of the project at the stage of data collection and analysis.

Conflict of interest: Data collection by Sequence HC Partners was funded by MSD Poland (MSD Polska Sp. $z$ o.o.). The Authors did not receive any remuneration for their participation in this research project.

\section{References}

1. Perk J, De Backer G, Gohlke H, et al. European Association for Cardiovascular Prevention \& Rehabilitation (EACPR), ESC Committee for Practice Guidelines (CPG). European Guidelines on cardiovascular disease prevention in clinical practice (version 2012). The Fifth Joint Task Force of the European Society of Cardiology and Other Societies on Cardiovascular Disease Prevention in Clinical Practice (constituted by representatives of nine societies and by invited experts). Eur Heart J. 2012; 33(13): 1635-1701, doi: 10.1093/eurheartj/ehs092, indexed in Pubmed: 22555213.

2. Yusuf S, Hawken S, Ounpuu S, et al. INTERHEART Study Investigators. Effect of potentially modifiable risk factors associated with myocardial infarction in 52 countries (the INTERHEART study): case-control study. Lancet. 2004; 364(9438): 937-952, doi: 10.1016/S0140-6736(04)17018-9, indexed in Pubmed: 15364185.

3. Zdrojewski Ł, Zdrojewski T, Rutkowski M, et al. Prevalence and control of cardiovascular risk factors in Poland. Assumptions and objectives of the NATPOL 2011 Survey. Kardiol Pol. 2013; 71(4): 381-392, doi: 10.5603/KP.2013.0066, indexed in Pubmed: 23788344.

4. Baigent C, Blackwell L, Emberson J, et al. Cholesterol Treatment Trialists' (CTT) Collaboration. Efficacy and safety of more intensive lowering of LDL cholesterol: a meta-analysis of data from 170,000 participants in 26 randomised trials. Lancet. 2010; 376(9753): 1670-1681, doi: 10.1016/S0140-6736(10)61350-5, indexed in Pubmed: 21067804.

5. Graham I, Atar D, Borch-Johnsen K, et al. European Society of Cardiology (ESC) Committee for Practice Guidelines (CPG). European guidelines on cardiovascular disease prevention in clinical practice: executive summary: Fourth Joint Task Force of the European Society of Cardiology and Other Societies on Cardiovascular Disease Prevention in Clinical Practice (Constituted by representatives of nine societies and by invited experts). Eur Heart J. 2007; 28(19): 2375-2414, doi: 10.1093/eurheartj/ ehm316, indexed in Pubmed: 17726041.

6. Reiner Ž, Catapano AL, De Backer G, et al. European Association for Cardiovascular Prevention \& Rehabilitation, ESC Committee for Practice Guidelines (CPG) 2008-2010 and 2010-2012 Committees. ESC/EAS Guidelines for the management of dyslipidaemias: the Task Force for the management of dyslipidaemias of the European Society of Cardiology (ESC) and the European Atherosclerosis Society (EAS). Eur Heart J. 2011; 32(14): 1769-1818, doi: 10.1093/eurheartj/ehr158, indexed in Pubmed: 21712404.

7. Catapano AL, Graham I, De Backer G, et al. Authors/Task Force Members:, Authors/Task Force Members, Additional Contributor. 2016 ESC/EAS Guidelines for the Management of Dyslipidaemias. Eur Heart J. 2016; 37(39): 2999-3058, doi: 10.1093/ eurheartj/ehw272, indexed in Pubmed: 27567407. 
8. Piepoli MF, Hoes AW, Agewall S, et al. Authors/Task Force Members, Additional Contributor, Document Reviewers. 2016 European Guidelines on cardiovascular disease prevention in clinical practice: The Sixth Joint Task Force of the European Society of Cardiology and Other Societies on Cardiovascular Disease Prevention in Clinical Practice (constituted by representatives of 10 societies and by invited experts) Developed with the special contribution of the European Association for Cardiovascular Prevention \& Rehabilitation (EACPR). Eur Heart J. 2016; 37(29): 2315-2381, doi: 10.1093/eurhearti/ehw106, indexed in Pubmed: 27222591.

9. Michalak M, Kołtowski $€$, Jaworski $€$, et al. Is treatment of hypercholesterolemia optimal? Results of the survey assessing ambulatory treatment of hypercholesterolemia in Poland. Pol Przegl Kardiol. 2010; 12: 207-211.

10. Kołtowski Ł, Michalak M, Jaworski Ł, et al. Do we know how to use ezetimibe in the everyday ambulatory practice? Polish cardiologists survey. Pol Przegl Kardiol. 2010; 12: 269-274.

11. Kapłon-Cieślicka A, Filipiak KJ. Treatment of hypercholesterolemia in ambulatory care in Poland. Chor Ser Nacz. 2015; 12: 240-248.

12. Kastelein JJP, Akdim F, Stroes ESG, et al. ENHANCE Investigators. Simvastatin with or without ezetimibe in familial hypercholesterolemia. N Engl J Med. 2008; 358(14): 1431-1443, doi: 10.1056/NEJMoa0800742, indexed in Pubmed: 18376000.

13. Cannon CP, Blazing MA, Giugliano RP, et al. IMPROVE-IT Investigators. Ezetimibe added to statin therapy after acute coronary syndromes. N Engl J Med. 2015; 372(25): 2387-2397, doi: 10.1056/NEJMoa1410489, indexed in Pubmed: 26039521.

14. Ginsberg HN, Elam MB, Lovato LC, et al. ACCORD Study Group. Effects of combination lipid therapy in type 2 diabetes mellitus. N Engl J Med. 2010; 362(17): 1563-1574, doi: 10.1056/ NEJMoa1001282, indexed in Pubmed: 20228404.

15. Keech A, Simes RJ, Barter P, et al. FIELD study investigators. Effects of long-term fenofibrate therapy on cardiovascular events in 9795 people with type 2 diabetes mellitus (the FIELD study): randomised controlled trial. Lancet. 2005; 366(9500): 1849-1861, doi: 10.1016/S0140-6736(05)67667-2, indexed in Pubmed: 16310551.

16. Food and Drug Administration. FDA Drug Safety Communication: new restrictions, contraindications, and dose limitations for
Zocor (simvastatin) to reduce the risk of muscle injury. http:// www.fda.gov/Drugs/DrugSafety/ucm256581.htm (12.12.2015).

17. Food and Drug Administration. FDA Drug Safety Communication: Important safety label changes to cholesterol-lowering statin drugs. http://www.fda.gov/Drugs/DrugSafety/ucm293101. htm (12.12.2015).

18. Sukhija R, Prayaga S, Marashdeh M, et al. Effect of statins on fasting plasma glucose in diabetic and nondiabetic patients. J Investig Med. 2009; 57(3): 495-499, doi: 10.2310/JIM.0b013e318197ec8b, indexed in Pubmed: 19188844.

19. Erqou S, Lee CC, Adler AI, et al. Statins and glycaemic control in individuals with diabetes: a systematic review and meta-analysis. Diabetologia. 2014; 57(12): 2444-2452, doi: 10.1007/s00125-0143374-x, indexed in Pubmed: 25245638.

20. Aiman U, Najmi A, Khan RA. Statin induced diabetes and its clinical implications. J Pharmacol Pharmacother. 2014; 5(3): 181-185, doi: 10.4103/0976-500X.136097, indexed in Pubmed: 25210397.

21. Cederberg H, Stančáková A, Yaluri N, et al. Increased risk of diabetes with statin treatment is associated with impaired insulin sensitivity and insulin secretion: a 6 year follow-up study of the METSIM cohort. Diabetologia. 2015; 58(5): 1109-1117, doi: 10.1007/s00125-015-3528-5, indexed in Pubmed: 25754552.

22. Sliz D, Filipiak KJ, Naruszewicz M, et al. Standards of statin usage in Poland in high-risk patients: 3ST-POL study results. Kardiol Pol. 2013; 71(3): 253-259, doi: 10.5603/KP.2013.0037, indexed in Pubmed: 23575780.

23. Kotseva K, Wood D, De Backer G, et al. EUROASPIRE Study Group. EUROASPIRE III: a survey on the lifestyle, risk factors and use of cardioprotective drug therapies in coronary patients from 22 European countries. Eur J Cardiovasc Prev Rehabil. 2009; 16(2): 121-137, doi: 10.1097/HJR.0b013e3283294b1d, indexed in Pubmed: 19287307.

24. Kotseva K, Wood D, De Bacquer D, et al. EUROASPIRE Investigators. EUROASPIRE IV: A European Society of Cardiology survey on the lifestyle, risk factor and therapeutic management of coronary patients from 24 European countries. Eur J Prev Cardiol. 2016; 23(6): 636-648, doi: 10.1177/2047487315569401, indexed in Pubmed: 25687109. 